\title{
ESTADO ACTUAL DE LA INGENIERIA DE TEJIDOS EN UROLOGÍA. REVISIÓN DE LA LITERATURA.
}

\author{
E. DE DIEGO RODRÍGUEZ, A. VILLANUEVA PEÑA, A. ROCA EDREIRA*, \\ B. MARTÍN GARCÍA*, A. MEANA INFIESTA**, S. GÓMEZ LLAMES**
}

Servicio de Urología. Hospital Comarcal de Laredo. Cantabria. *Hospital Universitario Marqués de Valdecilla. Santander. Cantabria. ${ }^{* *}$ Centro Comunitario de Sangre y Tejidos del Principado de Asturias. Oviedo. Asturias.

Actas Urol Esp. 28 (9): 636-645, 2004

\section{RESUMEN}

ESTADO ACTUAL DE LA INGENIERÍA DE TEJIDOS EN UROLOGÍA. REVISIÓN DE LA LITERATURA

En la década de los 80 surge un nuevo campo de la medicina que aplica los principios del cultivo celular a polímeros sintéticos biodegradables de soporte con el fin de crear sustitutos biológicos autólogos que puedan mejorar, mantener o restaurar la función de órganos o tejidos dañados.

La Ingeniería Tisular constituye una nueva disciplina en plena fase de desarrollo, especialmente en USA, con múltiples potenciales aplicaciones en las diferentes especialidades médicas.

Nuestra especialidad no puede permanecer ajena al interés y esperanzador futuro suscitado por esta nueva ciencia.

En el presente trabajo realizamos una amplia revisión bibliográfica en Medline con objeto de conocer los antecedentes, estado actual y las posibles aplicaciones futuras de la Ingeniería de Tejidos en Urología.

PALABRAS CLAVE: Cultivo in vitro. Cultivo celular. Urotelio. Ingeniería tisular.

\section{ABSTRACT \\ CURRENT STATE OF THE TISSUE ENGINEERING IN UROLOGY. REVISION OF THE LITERATURE}

In the eighties a new field of the medicine appears wich applies the principles of cellular cultivation to synthetic biodegradable polymers scaffolds with the purpose of creating autologous biological substitutes that could improve, maintain or restore the function of organs or damaged tissues.

The Tissue Engineering constitutes a new discipline in full phase of development especially in USA, with multiple potential applications in several medical specialities.

Our speciality can't remain indifferent to interest and encouraging future originated by this new science.

In this work we have made a wide bibliographical revision in the Medline to know the antecedents, current state and the possible future applications of Tissue Engineering in Urology.

KEY WORDS: In vitro culture. Cell culture. Urothelium. Tissue engineering. 


\section{ANTECEDENTES}

Desde hace muchos años uno de los principales retos de la medicina ha sido el hecho de poder mantener, restaurar o mejorar la función de órganos o tejidos dañados o perdidos en la anatomía humana.

Ya en 1879 Ljunggren mantenía fragmentos de piel viable en líquido ascítico como posible material para cubrir heridas extensas con objeto de acelerar su curación ${ }^{1}$.

Es a partir de 1950 cuando se comienza a desarrollar la idea de poder regenerar un tejido a partir de una pequeña porción del mismo mediante la aplicación de una serie de técnicas de laboratorio que permitirían la recolección, cultivo y multiplicación celular para posteriormente reconstruir ese tejido, reproduciendo las condiciones físicas y ambientales adecuadas para tal fin.

Puesto que la piel es uno de los tejidos más abundantes del organismo y a la vez más expuesto al medio ambiente, la necesidad de crear un sustituto ideal para la misma ha hecho que a lo largo de la historia numerosos equipos de investigadores hayan intentado obtener un tejido que pudiese sustituir a la piel dañada.

De esta forma las primeras referencias a las técnicas de cultivo celular aparecen en 1960 cuando Maltoltsy introduce fragmentos de piel completa en medios de cultivo o en otros órganos con el fin de obtener una proliferación celular ${ }^{1}$.

En 1975 Reinwald y Green ${ }^{2}$ establecen las condiciones idóneas para expandir en cultivo indefinidamente células epiteliales a partir de una línea de queratinocitos derivados de un teratoma de ratón; a su vez introducen la teórica posibilidad de poder aplicar dichas técnicas de igual manera a otros epitelios diferentes al cutáneo.

En 1980 Banks-Schelegel ${ }^{3}$ demuestra la viabilidad del epitelio obtenido in vitro como injerto libre en el animal de experimentación. Shouthgate $^{4}$ en 1987 describe un método basado en las técnicas de Reinwald y Green para el cultivo in vitro de células epiteliales de la cavidad bucal. De Luca $^{5}$ y Langdon ${ }^{6}$ aplicarán clínicamente estos tejidos obtenidos in vitro.

La consolidación y el perfeccionamiento de las técnicas de cultivo in vitro de queratinocitos han revolucionado en nuestros días el tratamiento de los grandes quemados ${ }^{7-9}$, la corrección de defectos cutáneos importantes ${ }^{10}$ o el tratamiento de úlceras crónicas ${ }^{11}$, de forma que un periodo de tiempo relativamente corto, a partir de una biopsia mínima de piel sana se puede obtener una cantidad importante de un tejido autólogo que obviará la falta de ese tejido así como el rechazo inmunológico. En el momento actual más del 30\% de las Unidades de Quemados de Europa utilizan con éxito este tipo de técnicas.

Desde que en 1975 se introdujese la teórica posibilidad de aplicar estas técnicas a epitelios diferentes al cutáneo, los investigadores comenzaron a plasmar experimentalmente dicha hipótesis; en general las referencias encontradas en la literatura hacen alusión al cultivo experimental de diferentes epitelios: tiroideo ${ }^{12}$, traqueal $^{13}$, bronquial $^{14}$, corneal ${ }^{15}$, digestivo ${ }^{16}$, sin poder generalizar su uso hacia la práctica clínica.

Paralelamente a estos hechos, y como una línea de investigación a parte, en 1954 Murray $^{17}$ desarrolla en el Peter Bent Brigham Hospital de Boston el primer trasplante de un órgano sólido en dos sujetos genéticamente idénticos; en 1959 se trasplanta el primer riñón en pacientes heterogénicos y en 1984 surge el programa de trasplante hepático pediátrico en el Children's Hospital de Boston. La era del trasplante había comenzado y ya era víctima de su propio éxito, la escasez de órganos a trasplantar.

En 1985 Russell ${ }^{18}$ introduce el concepto de trasplante celular selectivo, Burke ${ }^{19}$ diseña una piel bioartificial sobre una matriz bidimensional de colágeno y Vacanti, ${ }^{20}$ recogiendo las experiencias previas, aplica estos principios a sistemas biodegradables tridimensionales para la obtención de órganos y tejidos; surge así en 1985 el Laboratorio de Ingeniería de tejidos y trasplantes del Children's Hospital de Boston en colaboración con el Laboratorio de Polímeros biodegradables del Instituto Tecnológico de Massachussets.

Aparece así una nueva metodología de trabajo (Fig.1), procediéndose a la recolección de células aisladas o disgregadas del órgano o tejido donante, las cuales van a ser cultivadas y sembradas sobre polímeros sintéticos biodegradables que actúan de soporte para las mismas, siendo posteriormente devueltas al organismo donante. Vacanti ${ }^{21}$ bautiza a esta nueva metodología como "neomorfogénesis quimérica". 


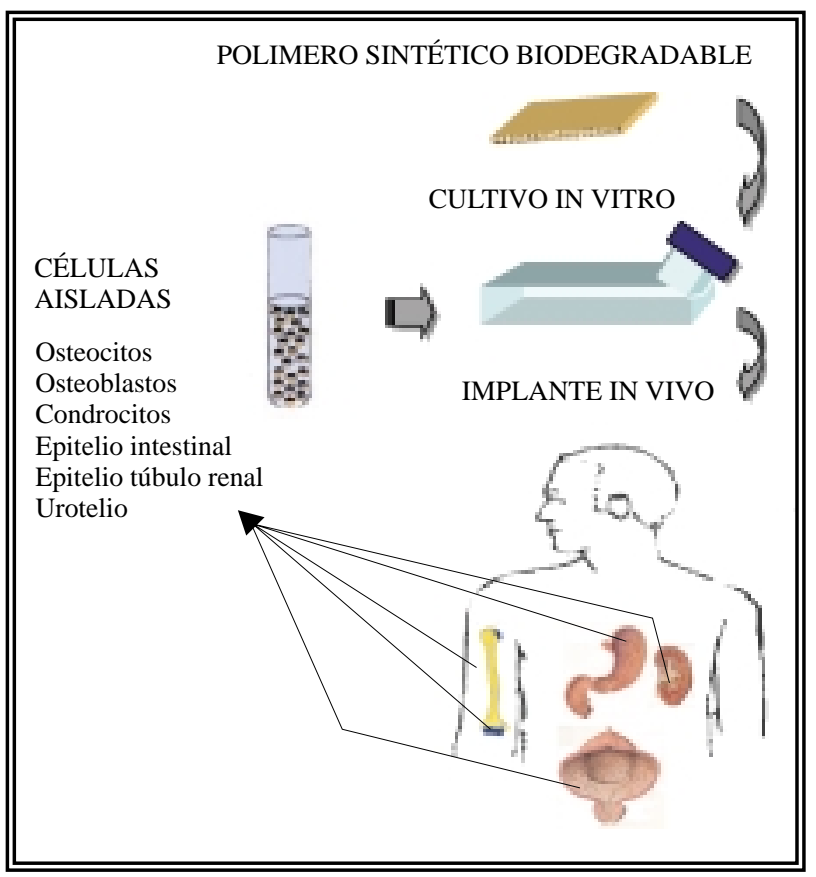

FIGURA 1. Metodología de la Ingenieria Tisular.

Surge un nuevo campo en la medicina, la Ingeniería Tisular, la cual se define como un campo interdisciplinario que aplica los principios de la biología e ingeniería celular hacia la creación o desarrollo de sustitutos biológicos que restauren, mantengan o mejoren la función de órganos o tejidos dañados ${ }^{22,23}$.

A pesar de su juventud y de su "estado embrionario de desarrollo 21 ", esta nueva disciplina cuenta ya con más de 2500 científicos en EEUU, con un presupuesto anual de más de 450 millones de dólares y un crecimiento anual del $22,5 \%$, cifras que no hacen si no poner de manifiesto la enorme importancia otorgada a este nuevo campo ${ }^{24}$.

Establecidos los principios teóricos de esta nueva ciencia, los investigadores aplican éstos experimentalmente:

- Vacanti ${ }^{25}$ y Puelacher ${ }^{26}$ cultivan e implantan condrocitos. Brittberg ${ }^{27}$ describe el trasplante de condrocitos autólogos humanos, hecho importante para la cirugía plástica reconstructiva.

- $\mathrm{Cao}^{28}$ implanta en ratones atímicos células obtenidas de tendones, consiguiendo un tejido de características idénticas al colágeno, apuntando un futuro potencial en la cirugía ortopédica.

- Mooney y Vacanti ${ }^{29}$ aíslan osteocitos y osteoblastos obteniendo un tejido con una trabeculación ósea normal.
- Organ ${ }^{30}$ aisla y cultiva sobre polímeros sintéticos células epiteliales procedentes del tracto digestivo con posibles aplicaciones en la cirugía digestiva.

- Breuer ${ }^{31}$ en 1995 crea la primera válvula cardiaca mediante técnicas de ingeniería tisular con buenos resultados funcionales.

Pese al enorme interés suscitado en la década de los 70 con la aparición de las nuevas técnicas de cultivo celular el urotelio no parecía, al menos inicialmente, el tejido idóneo para su aplicación, de forma que las únicas experiencias existentes se basaban en el cultivo de urotelio neoplásico, lo que obviamente limitaba su aplicación clínica.

Autores como Elliot ${ }^{32}$ y Stone $^{33}$ en 1975, Bonnar $^{34}$ en 1977, Chlapowski ${ }^{35}$ en 1979, Kwnoles $^{36}$ y Pauli ${ }^{37}$ en 1980 o Messing ${ }^{38}$ en 1982, intentan la obtención de urotelio no neoplásico en el laboratorio aplicando diferentes técnicas, siendo el denominador común en todos ellos el encontrarse con una recolección celular inadecuada, un escaso potencial de crecimiento y pobre capacidad de diferenciación de las células así como frecuentes contaminaciones de los cultivos por células estromales, hechos que conducían invariablemente al fracaso de los cultivos.

En 1983 Reznikoff ${ }^{39}$ y un año después Schmit ${ }^{40}$ perfeccionan la metodología de recolección de células uroteliales, mejoran los medios y las condiciones de cultivo y logran obtener monocapas de células uroepiteliales confluentes que pueden mantener y subcultivar. Posteriormente Hutton $^{41}$ y después Southgate ${ }^{42}$ introducen nuevos factores a los medios de cultivo comprobando el efecto ejercido sobre la proliferación, estratificación y diferenciación de las células uroteliales, mejorando el porcentaje de éxitos de los cultivos.

En 1992-93 Atala ${ }^{43,44}$ en Boston introduce los principios de la recién constituida ingeniería tisular a la Urología; el autor establece un método de recolección de células uroteliales disgregadas a partir de muestra de tejido urotelial, que siembra sobre mallas biodegradables de ácido poliglicólico, manteniéndolas en cultivo a $37^{\circ} \mathrm{C}$ en una atmósfera al $5 \%$ de $\mathrm{CO}_{2}$ durante 1 a 4 días hasta que se produzca la adhesión de las células a la malla momento en el que son injertadas en ratones atímicos para estudiar la viabilidad del implante. Nos encontramos ante la primera refe- 
rencia sobre la creación de un urotelio obtenido in vitro susceptible de ser trasplantado mediante técnicas de ingeniería tisular.

\section{ESTADO ACTUAL DE LA INGENIERÍA DE TEJ IDOS EN UROLOGÍA}

Dos fechas pueden entenderse como claves, a nuestro entender, en la actual situación de la Ingeniería Tisular en Urología.

En primer lugar Reinwald y Green ${ }^{2}$ en 1975 establecen las condiciones idóneas para poder expandir en cultivo indefinidamente células epiteliales cutáneas, apuntando la posibilidad de aplicar estas técnicas a los diferentes epitelios. De esta forma Romagnoli ${ }^{45,46}$ en 1990 y después en 1993 aporta las primeras referencias sobre la aplicación de las técnicas de cultivo de epitelios al urotelio, aplicando los principios introducidos por Reinwald y Green al epitelio uretral; el autor obtiene láminas de células uroteliales que aplica clínicamente para la corrección de 10 casos de hipospadias con resultados excelentes, si bien los periodos de seguimiento fueron cortos y sin detallar el difícil manejo de los tejidos obtenidos in vitro.

Se asistía, no obstante, a un hecho sin precedentes en la Urología pues a partir de una biopsia mínima obtenida con anestesia local, mediante la aplicación de las técnicas de cultivo de tejidos se lograba obtener una cantidad importante de urotelio autólogo como para obviar las importantes limitaciones que las uretroplastias plantean en no pocas ocasiones como consecuencia de la falta de tejidos nativos viables.

En segundo lugar en 1992-93 Atala $^{43,44}$ introduce los principios de la Ingeniería Tisular en la Urología, aplicando las técnicas de cultivo celular de urotelio sobre polímeros sintéticos biodegradables obteniendo así una estructura apta para trasplantar. Quedaba planteada de esta manera la hipótesis de poder obtener estructuras génitourinarias in vivo como uréter, vejiga, uretra, a partir de poblaciones celulares obtenidas por biopsia de las mismas, las cuales son sembradas y cultivadas sobre matrices biodegradables para posteriormente ser implantadas de nuevo en el huésped.

La aplicabilidad de las técnicas de Ingeniería tisular trasciende a varios tipos de entidades urológicas que seguidamente revisaremos.

\section{URETRA}

En 1995 Cilento $^{47}$ describe la utilización de un polímero biodegradable de ácido poliglicólico para la realización de uretroplastias, basándose en la capacidad regenerativa del epitelio uretral; posteriormente el mismo autor ${ }^{48}$ utiliza dicho polímero sembrado de células uroteliales y musculares que implanta en uretras de conejo sin evidenciar estenosis ni fístulas en su seguimiento, con una estructura anátomo-patológica normal.

En 1999 Chen $^{49}$ utiliza un nuevo sustituto uretral consistente en una matriz de colágeno acelular obtenida a partir de vejiga de cerdo, realizando 10 uretroplastias en conejo, con buenos resultados. Atala ${ }^{50}$ aplicará clínicamente este material realizando 4 uretroplastias en pacientes previamente intervenidos; tras un periodo de seguimiento de 22 meses, únicamente describe la aparición de una fístula que se corrigió con cirugía convencional. El calibre uretral, estudio histológico y apariencia macroscópica fueron normales. Hasta la fecha unos 60 pacientes (adultos y niños) han sido tratados con este biomaterial, con excelentes resultados ${ }^{51}$.

Al parecer el mismo autor utiliza dicho soporte sembrado de células uroteliales para la cirugía uretral en humanos sin haber publicado aún los resultados $^{52}$. El-Kassaby ${ }^{53}$ aporta 28 pacientes con un seguimiento medio de 37 meses, con 24 resultados excelentes, 4 reestenosis y una fístula subcoronal.

Kropp $^{54}$ investiga la utilización de otro biomaterial como posible sustituto uretral, la submucosa intestinal, realizando 8 uretroplastias en parche en conejo con muy buenos resultados. De Filippo ${ }^{55}$ utiliza matrices de colágeno acelulares tubularizadas, solas o sembradas de células, apreciando estenosis y retracción del injerto con las primeras y no así con las sembradas de células autólogas cultivadas.

\section{URÉTER}

Yoo $^{56}$ en 1995 establece un diseño experimental en perros de los cuales obtiene células uroteliales y musculares a partir de biopsias de pared vesical; dichas células son sembradas sobre ambas superficies de mallas de ácido poliglicólico, seguidamente realiza ureterectomías parciales, sustituyendo el defecto creado por el polímero 
siembra do de células autólogas. El estudio urográfico posterior puso de manifiesto la permeabilidad de la vía excretora y el estudio anatomopatológico evidenció la presencia de unas capa completa de células uroteliales revestidas por varias capas de células musculares bien conformadas.

Recientemente Amiel ${ }^{57}$ propone la creación de stents bioartificiales para la corrección de estenosis ureterales o uretrales mediante el cultivo de condrocitos procedentes de muestras de cartílago que siembra sobre estructuras cilíndricas de ácido poliglicólico, obteniendo una estructura autóloga de características físicas apropiadas para corregir estenosis sin originar los problemas de infección, tolerancia o desarrollo de cálculos que los materiales sintéticos originan a menudo.

Por último, a nivel experimental, se han realizado cultivos de células uroteliales y musculares de uréter ${ }^{58,59}$, estudiando la respuesta a diferentes agentes farmacológicos así como las interacciones entre ambos tipos celulares, sin aplicación clínica hasta el momento.

\section{VEJ IGA}

En 1995 Fujiyama $^{60}$ realiza una reconstrucción tridimensional de mucosa vesical a partir de una muestra de pared vesical. Obtiene células uroteliales aisladas de la mucosa de la muestra y diseña una submucosa bioartificial mediante un gel de colágeno tipo I y fibroblastos procedentes de la lámina propia de la muestra; sobre este tejido siembra las células uroteliales obteniendo asî una estructura tridimensional.

En 1996 Yoo $^{61}$, basándose en los trabajos previos de Atala ${ }^{43,44}$ diseña un modelo experimental de ampliación vesical en perros para lo cual obtiene células uroteliales y musculares a partir de biopsias de pared vesical de cada animal, las cuales cultiva y siembra sobre polímeros sintéticos degradables. Se practican cistectomías parciales en los animales, realizando cistoplastias con los polímeros sembrados de células autólogas. El estudio histológico puso de manifiesto un urotelio bien conformado revestido de varias capas de células musculares; el estudio urodinámico realizado evidenció una complianza vesical normal y un aumento medio de la capacidad vesical en torno al $30 \%$.
En otro estudio Zhang62 cultiva células uroteliales y musculares utilizando como soporte submucosa intestinal, evidenciando una menor retracción del injerto posiblemente debido al evitar las células cultivadas el contacto directo de la matriz con la orina. En esta misma línea, Loren $^{63}$ diseña un modelo de ampliación vesical en ovejas utilizando segmentos gastrointestinales demucosalizados sembrados de células uroteliales autólogas previamente recogidas y cultivadas con buenos resultados funcionales.

En 1998 Yoo $^{64}$ realiza un nuevo estudio practicando cistoplastias en 5 perros mediante submucosa vesical alogénica y en otros 5 con el mismo biomaterial sembrado de células uroteliales y musculares autólogas previamente recogidas y cultivadas de cada animal; funcionalmente se pudo comprobar como el aumento medio obtenido en la capacidad vesical fue del $95 \%$ en el segundo grupo respecto al 30\% encontrado en el primero.

Bajo esta premisas Oberpenning ${ }^{65}$ plantea la hipótesis de poder generar una neovejiga funcional a partir de una pequeña porción de la misma mediante ingeniería tisular.

Para ello el autor ${ }^{66}$ establece un diseño experimental con 3 grupos de perros a los que practica una cistectomía supratrigonal, a un primer grupo realiza un cierre simple de la vejiga, a un segundo practica una plastia vesical mediante un polímero biodegradable y al tercero realiza la misma plastia del anterior pero con el polímero sembrado de células uroteliales y musculares autólogas.

Se realizaron estudios cistográficos y urodinámicos previos a la cirugía y a los meses $1^{\circ}-4^{\circ}, 6^{\circ}$ y $11^{\circ}$ tras la misma. Los resultados observados pusieron de manifiesto una capacidad y una complianza vesical normal en le tercer grupo, donde inmunohistológicamente se pudo apreciar un urotelio bien conformado, revestido de varias capas de células musculares con inmunoexpresión de pancitoqueratinas, alfa-actina, desmina y uroplaquina III e incluso se pudo evidenciar la presencia de estructuras neurales mediante la positividad del anticuerpo S- 100 .

Schoeller ${ }^{67}$ propone recientemente el uso de colgajos vascularizados prefabricados sembrados de células uroteliales autólogas, apuntando su posible aplicación clínica. 
Por el momento no hay constancia de la aplicación clínica de estas técnicas en la patología vesical; Atala parece haber realizado 7 cistoplastias en humanos utilizando polímeros sintéticos biodegradables sembrados de células uroteliales y musculares autólogas, sin haberse publicado aún los resultados ${ }^{52}$.

El perfeccionamiento de las técnicas de Ingeniería Tisular puede que un futuro no lejano obvien las frecuentes y no deseadas complicaciones de las enterocistoplastias ${ }^{68,69}$.

\section{REFLUJ O VESICO-URETERAL}

En 1993 Atala $^{70}$ introduce un nuevo biomaterial para el tratamiento endoscópico del reflujo vésicoureteral; el autor propone el uso de un gel de alginato (copolímero de ácido glucorónico y manurónico) sembrado de condrocitos autólogos, diseñando un modelo experimental en 4 cerdos donde reproduce quirúrgicamente un reflujo unilateral en cada animal, seguidamente inyecta vía endoscópica 2-3 $\mathrm{ml}$ de gel de alginato en la región submeática del uréter refluente. El estudio radiológico posterior evidenció la corrección del reflujo así como la ausencia de hidronefrosis; el estudio histológico puso de manifiesto la presencia de cartílago subureteral bien conformado, sin evidenciarse rechazo ni migración del material a otros órganos o tejidos.

En la misma línea de investigación, de nuevo Atala $^{71}$ y Cilento $^{72}$ utilizan experimentalmente células de músculo detrusor autólogo, con idénticos resultados.

En 1998 Diamond y Caldamone ${ }^{73}$ desarrollan en primer ensayo clínico aprobado por la FDA para la corrección endoscópica del reflujo vésicoureteral en niños mediante la inyección de condrocitos autólogos cultivados; se trataron niños entre 1 y 15 años con grados de reflujo II (26\%) y III (50\%) fundamentalmente. Se trataron 46 uréteres describiéndose un porcentaje de éxitos del $57 \%$ (26 casos) tras la primera inyección; los 20 restantes recibieron una segunda inyección a los 3 meses con un 63\% de buenos resultados, de forma que en conjunto, a los 3 meses de seguimiento tras 1 ó 2 inyecciones el porcentaje global de curación fue en torno al 83\% sin describirse complicaciones significativas.

Por otra parte, ensayos clínicos en fase I se llevaron a cabo para la corrección de la incontinen- cia urinaria por deficiencia intrínseca del esfïnter mediante la inyección endoscópica de condrocitos autólogos cultivados en mujeres ${ }^{74}$. Los resultados fueron presentados en el International Society Meeting en Denver, donde se habian tratado un total de 32 mujeres con un porcentaje de éxitos del $84 \%$ a los 6 meses de seguimiento.

\section{RECONSTRUCCIÓN PENEANA}

En un intento de poder disponer de un tejido autólogo viable para la corrección de anomalías congénitas o lesiones traumáticas de pene, Kershen ${ }^{75,76}$ consigue cultivar e implantar en ratones atímicos células de músculo cavernoso humano, demostrando inmunohistoquímicamente su fenotipo muscular.

Park $^{77}$ cultiva conjuntamente células musculares de cuerpo cavernoso y células endoteliales procedentes de vena de cordón umbilical, siembra ambas en polimeros biodegradables que implanta en animales inmunodeprimidos apreciando indicios de la formación de estructuras luminales de células endoteliales recubiertas por células musculares con una proporción media músculo/endotelio de 1,98 $\pm 0,16: 1$, aproximadamente equivalente a la proporción 2:1 observada in vivo.

Falke $^{78}$ en otro trabajo obtiene una estructura totalmente autóloga, utilizando como soporte una matriz de colágeno acelular tridimensional obtenida por técnicas de lisis celular del cuerpo cavernoso del propio animal.

Kwon ${ }^{79}$ realiza implantes en cuerpo cavernoso de conejos con matrices acelulares de colágeno sembradas de células musculares de cuerpo cavernoso y de células endoteliales; tras 6 meses de seguimiento los parámetros funcionales encontrados (cavernosografía y cavernosometría) fueron normales.

\section{DISFUNCIÓN ERÉCTIL}

Se plantea la hipótesis de poder obtener un tejido autólogo con las características físicas adecuadas como para mantener una erección, pudiendo evitar los problemas de biocompatibilidad o rechazo de las actuales prótesis.

Bajo esta premisa, Yoo $^{80}$ cultiva condrocitos autólogos procedentes de muestras de cartílago sobre polímeros sintéticos de estructura cilíndrica de $2 \mathrm{~cm}$ de largo y 0,3 cm de diámetro, que 
implanta en ratones atímicos obteniendo una estructura blanquecina de tamaño similar al implante, con unas características biomecánicas adecuadas para mantener una erección. El mismo autor ${ }^{81}$ realiza 8 implantes bilateralmente en cuerpo cavernoso de conejo, demostrando tras diferentes periodos de injerto, una estructura cartilaginosa bien conformada, apta como para mantener una erección. Kim ${ }^{82}$ cultiva e implanta en ratones atímicos, condrocitos humanos procedentes de muestras de cartílago de pabellón auricular, obteniendo estructuras cartilaginosas autólogas de características mecánicas similares a las actuales prótesis de silicona.

Directrices futuras apuntan a la posible obtención de bioprótesis autólogas mediante estas técnicas que pudiesen paliar los problemas de biocompatibilidad existentes con las actuales prótesis.

\section{COMPLEJ O EXTROFIA VESICAL-EPISPADIAS}

La reconstrucción vésico-uretral en los niños afectos de esta grave malformación genética se enfrenta a la habitual carencia de tejidos urológicos nativos para tal fin; en esta línea Fauza ${ }^{83}$ diseña un modelo en ovejas de 90-95 días de gestación reproduciendo quirúrgicamente una extrofia vesical en los fetos. Mediante técnicas de videofetoscopia obtiene muestras de pared vesical de las cuales aislan células uroteliales y musculares que cultiva y siembra sobre mallas de ácido poliglicólico de 16 a $20 \mathrm{~cm}^{2}$. Al nacimiento de los animales establece 2 grupos, realizando un cierre simple de la vejiga al primero de ellos; al segundo grupo realiza una reconstrucción vesical mediante las mallas sembradas de células cultivadas. El estudio cistográfico, urodinámico e histológico realizado puso de manifiesto unas vejigas normales en estos aspectos en el segundo grupo.

Quizá una futura aplicación práctica de este modelo pudiese facilitar la difícil reconstrucción génito-urinaria al nacimiento de estos niños al poder disponer de un tejido autólogo suficiente para tal fin ${ }^{84}$.

\section{INSUFICIENCIA RENAL TERMINAL}

Uno de los problemas fundamentales del trasplante renal es la escasez de unidades renales a trasplantar, lo que ha obligado a la utilización de riñones subóptimos o a la investigación del trasplante de órganos de otras especies.

Los investigadores intentan aplicar las técnicas de ingeniería tisular al complejo órgano renal; Atala $^{85}$ procede experimentalmente a la toma de muestras de corteza renal en animales, obteniendo por homogeneización, suspensiones purificadas de células epiteliales de túbulo proximal, distal y glomérulo, las cuales son sembradas sobre polímeros sintéticos, cultivadas e implantadas en ratones atímicos, evidenciando la formación de "estructuras renales" capaces de excretar niveles elevados de ácido úrico y creatinina en un fluido amarillento semejante a la orina.

Surge la posibilidad de poder generar túbulos bioartificiales mediante el cultivo de células epiteliales de túbulo proximal ${ }^{86,87}$ o de células madre ${ }^{88}$, originando estructuras in vitro capaces de mantener el equilibrio hidroelectrolítico al conservar las células su capacidad reabsortiva ${ }^{89,90}$.

\section{TÉCNICAS DE MICROENCAPSULACIÓN CELULAR}

Básicamente estos procedimientos consisten en la cobertura, mediante materiales biodegradables, de tipos celulares con funciones específicas, las cuales son mantenidas en el huésped al disminuir o anular la respuesta inmune al implante ${ }^{91}$.

En Urología existe una patología subsidiaria de la potencial aplicación de estas técnicas, el hipogonadismo $^{92}$. Se procede al aislamiento y purificación de células de Leyding, las cuales son suspendidas en una solución de alginato y cloruro cálcico hasta conseguir su gelificación, siendo tratadas después con gonadotropina coriónica humana durante 24 horas; las microesferas fueron inyectadas en animales castrados, observándose niveles adecuados de testosterona en las determinaciones séricas practicadas posteriormente ${ }^{93}$.

\section{CARACTERIZACIÓN DEL EPITELIO URINARIO EXPANDIDO IN VITRO}

Las propiedades biológicas del epitelio de transición no neoplásico no son bien conocidas. No se han definido aún los mecanismos o señales reguladoras del inicio de la reepitelización a nivel de pelvis renal, uréter, vejiga o uretra; de igual forma se han identificado pocos marcadores moleculares 
específicos de diferenciación uroepitelial definitiva. Estas propiedades han sido bien establecidas en otros epitelios al poder ser expandidos fácilmente en cultivo, pudiéndose determinar experimentalmente mecanismos de diferenciación, acción de mitógenos o respuesta a factores de crecimiento.

Establecidas las condiciones idóneas para el cultivo in vitro mantenido de células uroteliales, Cilento $^{94}$ establece una caracterización fenotípica y citogenética de epitelio vesical humano expandido in vitro, confirmando el fenotipo urotelial mediante la marcación inmunofluorescente con anticuerpos anticitoqueratina de reacción amplia y anticuerpo anti-citoqueratina 7 , presente en la mucosa vesical in vivo; realiza análisis cromosómico de las células uroteliales en las divisiones 3 y 6 sin observar anormalidades en el tintado con Giemsa de cromosomas en metafase.

Liebert ${ }^{95}$ realiza una comparación de la expresión antigénica presentada en el urotelio humano in vivo y el cultivado in vitro utilizando un panel de anticuerpos monoclonales específicos y anticuerpos anti-grupos sanguíneos, observando una menor expresión en el epitelio cultivado de antígeno AN43 y antígeno A, debido posiblemente a una menor diferenciación de las células cultivadas.

Freeman ${ }^{96}$ argumenta la independencia de los cultivos de células uroepiteliales a la acción del factor de crecimiento epidérmico (EGF) aislando una proteína que se une selectivamente al receptor del EGF, activándole, que denomina factor de crecimiento epidérmico like inhibidor de la heparina (HB-EGF), el cual es secretado por las células uroepiteliales en cultivo, constituyendo un regulador autocrino del crecimiento de las mismas, describiendo ${ }^{97}$ otros como la anfiregulina o el factor de crecimiento transformador $\alpha$ (TGF- $\alpha$ ).

\section{CONCLUSIONES}

La Ingeniería de Tejidos constituye un campo multidisciplinar en plena fase de desarrollo con una potencial aplicación clínica casi ilimitada ${ }^{98}$.

La Urología no es ajena al interés suscitado por esta emergente disciplina, habiendo presentado en unos pocos años un importante avance experimental en varios campos, con incluso puntuales aplicaciones clínicas, consolidando a su vez las numerosas indicaciones de estas técnicas en nuestra especialidad ${ }^{99,100}$.
A pesar de su "juventud", la Ingeniería Tisular abre un esperanzador abanico de posibilidades en la cirugía reconstructiva urológica ${ }^{101,102}$, que sin duda contribuirá, en un futuro próximo, a evitar las frecuentes y no deseadas complicaciones que el uso de tejidos heterólogos o sintéticos origina en el aparato urinario.

\section{REFERENCIAS}

1. Navsaria HA, Sexton C, Bouvard V, Leigh IM. Growth of keratinocytes with a 3T3 feeder layer: basic techniques. En Leigh I.M., Watt F.M. directores. Keratinocyte Methods. Cambridge University Press 1994: 2-12.

2. Rheinwald JG, Green H. Serial cultivation of strains of human epidermal keratinocytes: the formation of keratinising colonies from single cells. Cell 1975;6:331-334.

3. Banks-Schlegel S, Green H. Formation of epidermis by serially cultivated human epidermal cells transplanted as an epithelium to athymic mice. Transplantation 1980; 29(4):308-311.

4. Southgate J, Williams HK, Tredjdosiewic LK, Hodges GM. Primary culture of human oral epithelial cells: growth requirements and expression of differentiated characteristics. Lab Inves 1987:56(2):211-233.

5. De Luca M, Albanesse E, Megna M, Cancedda R, Mangiante PE, Cadoni A, Franci AT. Evidence that human oral epithelium reconstituted in vitro and transplanted onto patients with defects in the oral mucosa retains properties of the original donor site. Transplantation 1990;50(3):454-459.

6. Langdon JD, Leigh IM, Navsaria HA. Autologous oral keratinocyte grafts in the mouth. Lancet 1990;335:1472-1473.

7. Myers S, Navsaria H, Sanders R, Grenn C, Leigh IM. Transplantation of keratinocytes in the treatment of wounds. Am J Surg 1995;170:75-83.

8. Sheridan RL, Tompkims R. Cultured autologous epithelium in patients with burns of ninety percent or more of the body surface. J Traumatol 1995;38(1):48-50.

9. Rose JK, Herndon DN. Advances in the treatment of burn patients. Burns 1997;23:S19-S26.

10. Gallico GG, O'Connor NE, Compton CC. Cultured epithelial autografts for giant congenital naevi. Plast Reconstr Surg 1989;84:1-9.

11. Limat A, Mauri D, Hunziker T. Successful treatment of chronic leg ulcers with epidermal equivalents generated from cultured autologous outer root sheat cells. J Invest Dermatol 1996;107(1):128-135.

12. Toda S, Sugihara H. Reconstruction of thyroid follicles from isolated porcine follicle cells in three-dimensional collagen gel culture. Endocrinology 1990;126:2027-2034.

13. Duff BE, Wenig BL, Applebaun EL, Yeates DB, Wenig BM, Holinger LD. Tracheal reconstruction using a epithelial equivalent. Laryngoscope 1994;104:409-414.

14. Sugihara H, Toda S, Miyabara S, Fujiyama C, Yonemitsu N. Reconstruction of alveolus-like structure from alveolar tipe II epithelial cells in three-dimensional collagen gel matrix culture. Am J Pathol 1993;142:783-792.

15. Minami Y, Sugihara H, Oono S. Reconstruction of cornea in three-dimensional collagen gel matrix culture. Invest Ofthalmol 1993;34:2316-2324.

16. Organ GM, Mooney DJ, Hansen LK. Desing and transplantation of enterocyte polymer constructs: a small animal model for neointestinal remplacement in short bowel syndrome. Surg Forum 1993;45:432-436. 
17. Murray JE, Merrill JP, Harrison JH. Renal homotransplantation in identical twins. Surg Forum 1955;6:432-436.

18. Rusell PS. Selective transplantation. Ann Surg 1985;201: 255-262.

19. Burke JF, Yannas IV, Quimby WC, Bondoc CC, Jung WK. Successful use of a physiologically acceptable artificial skin in the treatment of extensive burn injury. Ann Surg $1981 ; 194: 413-418$.

20. Vacanti JP, Morse MA, Saltzman WM, Domb AJ, PérezAtayde A, Langer R. Selective cell transplantation using bioabsorbable artificial polymers as matrices. J Pediatr Surg 1988;23:3-9.

21. Vacanti JP. Beyond transplantation. Ann Surg 1988;123 545-549.

22. Vacanti JP, Langer R. Tissue engineering: the design and fabrication of living replacement devices for surgical reconstruction and transplantation. Lancet 1999;354:32-34.

23. Langer R, Vacanti JP. Tissue engineering: the challenges ahead. Sci Am 1999;280(4):86-89.

24. Lysaght MJ, Nguy N, Sullivan K. An economic survey of the emergin tissue engineering industry. Tissue Eng 1998;4:231-234.

25. Vacanti CA, Langer R, Schloo B, Vacanti JP. Synthetic polymers seeded with condrocytes provide a template for new cartilage formation. Plastic Reconstruct Surg 1991;88:753-759.

26. Puelacher WC, Vacanti JP, Kim SW, Upton J, Vacanti CA. Fabrication of nasal implants using human shape-specific polymer scaffolds seeded with chondrocytes. Am Coll Surgeons Surg Forum 1993;44:678-680.

27. Brittberg M, Lindahl A, Nilsson A, Ohlsson C, Isaksson O, Peterson L. Treatment of deep cartilage defects in the knee with autologous chondrocyte transplantation. N Eng J Med 1994;331:889-895.

28. Cao Y, Vacanti JP, Ma PX et al. Generation of neo-tendon using synthetic polymers seeded with tenocites. Transplant Proc 1994;26:3390-3392.

29. Mooney DJ, Vacanti JP. Tissue engineering using cells and synthetic polymers. Transplant Rev 1993;7:153-162.

30. Organ GM, Vacanti JP. Alimentary tract. En Lanza RP Langer R, Vacanti JP. editores. Principles of tissue engineering. $2^{\mathrm{a}}$ edición. San Diego, California. Academic Press. 2000: 525-537.

31. Breuer CK, Schinoka T, Tanel RE et al. Tissue engineering lamb heart valve leaflets. Biotch Bioeng 1996;50:562-567.

32. Elliot AY, Stein N, Fraley EF. Technique for cultivation of transicional epithelium from mammaliam urinary bladder. In vitro 1975;11:251-254.

33. Stone KR, Paulson DF, Bonar RA, Reich CF. In vitro culture of epithelial cells derived from urogenital tissues. Urol Res 1975;2:149-153.

34. Bonar RA, Reich CF, Sharief Y. Canine urinary bladder epithelial cells: preparation for cell culture by enzyme dispersion. Urol Res 1977;5:87-94.

35. Chlapowski FJ, Haynes L. The growth and differentiation of transitional epithelium in vitro. J Cell Biol 1979;83:605-614.

36. Knowles MA, Hicks RM, Berry RJ, Milroy E. Organ culture of normal human bladder: choice of starting material and culture characteristics. Methods Cell Biol 1980;21:257-285.

37. Pauli BU, Anderson SN, Memoli VA, Kuettner KE. The isolation and characterization in vitro of normal epithelial cells, endothelial cells and fibroblasts from rat urinary bladder. Tissue Cell 1980;12:419-435.

38. Messing EM, Fahey JL, Dekernion JB, Bhutta S, Fahey J. Serum free medium for the in vitro growth normal and malignant urinary bladder epithelial cells. Cancer Res 1982; 42:2392-2397.

39. Reznikoff CA, Johnson MD, Norback DH, Bryan GT. Growth and characterization of normal human urothelium in vitro. In Vitro 1983;19:326-343.
40. Schmidt WW, Messing EM, Reznikoff CA. Cultures of normal human urothelial cells from ureters of perfused cadaver transplant kidneys. J Urol 1984;132:1262-1264.

41. Hutton KAR, Trejdosiewicz LK, Thomas DFM, Southgate J. Urothelial tissue culture for bladder reconstruction: a experimental study. J Urol 1993;150:721-725.

42. Southgate J, Hutton KAR, Thomas DFM, Trejdosiewicz LK. Normal human urothelial cells in vitro: proliferation and induction of stratification. Lab Inves 1994;71:583-594.

43. Atala A, Vacanti JP, Peters CA, Mandell J, Retik AB, Freeman MR. Formation of urothelial structures in vivo from dissociated cells attached to biodegradable polymer scaffolds in vitro. J Urol 1992;148:658-662.

44. Atala A, Freeman MR, Vacanti JP, Shepard J, Retik AB. Implantation in vivo and retrieval of artificial structures consisting of rabbit and human urothelium and human bladder muscle. J Urol 1993;150;608-612.

45. Romagnoli G, De Luca M, Faranda F, Bandelloni R, Franzi AT, Cataliotti F, Cancedda R. Treatment of posterior hypospadias by the autologous graft of cultured urethral epithelium. N Eng J Med 1990;323:527-530.

46. Romagnoli G, De Luca M, Faranda F, Franzi AT, Cancedda R. One-step treatment of proximal hypospadias by the autologous graft of cultured urethral epithelium. J Urol 1993;150:1204-1207.

47. Cilento BG, Retik AB, Atala A. Urethral reconstruction using a polymer mesh. J Urol 1995;153:371A. Abstract 571.

48. Cilento $\mathrm{BG}$, Retik $\mathrm{AB}$, Atala A. Urethral reconstruction using polymer scaffolds seeded with urothelial and smooth muscle cells. J Urol 1996;155:5 (suppl.).

49. Chen F, Yoo JJ, Atala A. Acellular collagen matrix as a possible of the shelf biomaterial for urethral repair. Urology 1999;54:407-410.

50. Atala A, Guzman L, Retik AB. A novel inert collagen matrix for hypospadias repair. J Urol 1999;162:1148-1151.

51. Atala A. Experimental and clinical experience with tissue engineering techniques for urethral reconstruction. Urol Clin North Am 2002;29(2):485-492.

52 . Friedrich MJ. Tissue engineering in the genitourinary system. JAMA 2000;283(19):2509.

53. El-Kassaby AW, Retik AB, Yoo JJ, Atala A. Urethral stricture repair with an off-the-shelf collagen matrix. J Urol 2003;169(1):170-173.

54. Kropp BP, Ludlow JK, Spicer D et al. Rabbit urethral regeneration using small intestinal submucosa onlay grafts. Urology 1998;52:138-142.

55. De Filippo RE, Yoo JJ, Atala A. Urethral replacement using cell seeded tubularized collagen matrices. J Urol 2002;168(4):1789-1792.

56. Yoo JJ, Satar N, Retik AB, Atala A. Ureteral replacement using biodegradable polymer scaffolds seeded with urothelial and smooth muscle cells. J Urol 1995;153:375A. Abstratc 585.

57. Amiel GE, Yoo JJ, Kim BS, Atala A. Tissue engineered stents created from chondrocytes. J Urol 2001;165:2091-2095.

58. Wolf JS, Soble JJ, Ratliff TL, Clayman RV. Ureteral cell cultures I: characterization and cellular interactions. J Urol 1996;156:1198-1203.

59. Wolf JS, Soble JJ, Ratliff TL, Clayman RV. Ureteral cell cultures II: collagen production and response to pharmacologic agents. J Urol 1996;156:2067-2072.

60. Fujiyama C, Masaki Z, Sugihara H. Reconstruction of the urinary bladder mucosa in three-dimensional collagen gel culture: fibroblast-extracellular matrix interactions on the differentiation of transitional epithelial cells. J Urol 1995; 153:2060-2067. 
61. Yoo JJ, Satar N, Atala A. Bladder augmentation using biodegradable polymer scaffolds ceded with urothelial and smooth muscle cells. J Urol 1996;155:336A. Abstract 103.

62. Zhang Y, Kropp BP, Moore $\mathrm{P}$ et al. Coculture of bladder urothelial and smooth muscle cells on small intestinal submucosa: potential applications for tissue engineering technology. J Urol 2000;164:928-935.

63. Lorenz C, Maier-Reif K, Back W, Hohl HP, Waag KL. Cultured urothelium in sheep bladder augmentation. Pediatr Surg Int 1996;11:456-461.

64. Yoo JJ, Meng J, Oberpenning F, Atala A. Bladder augmentation using allogenic bladder submucosa seeded with cells. Urology 1998;51:221-225.

65. Oberpenning F, Meng J, Yoo JJ, Atala A. Bladder replacement with tissue engineering neo-organs. Pediatrics 1997;100:10 (suppl.).

66. Oberpenning F, Meng J, Yoo JJ, Atala A. De novo reconstruction of a functional mammalian urinary bladder by tissue engineering. Nature Biotechnol 1999;17:149-155.

67. Schoeller T, Lille S, Stenz A et al. Bladder reconstruction using a prevascularized capsular tissue seeded with urothelial cells. J Urol 2001;165:980-985.

68. Atala A. Future trends in bladder reconstructive surgery. Semin Pediatr 2002;11(2):134-142.

69. Atala A. New methods of bladder augmentation. BJU Int 2000;85 suppl 3:134-142.

70. Atala A, Kim W, Paige KT, Vacanti JP, Retik AB. Endoscopic treatment of vesicoureteral reflux with a chondrocyte-alginate suspension. J Urol 1994;152:641-643.

71. Atala A, Cilento BG, Paige KT, Retik AB. Injectable alginate seeded with human bladder muscle cells as a potential treatment for vesicoureteral reflux. J Urol 1994;151:362A. Abstract 538 .

72. Cilento BG, Atala A. Treatment of reflux and incontinence with autologous chondrocytes and bladder muscle cells. Dialogues Pedriat Urol 1995;18:11-15.

73. Diamond DA, Caldamone AA. Endoscopic correction of vesicoureteral reflux in children using autologous chondrocytes: preliminary results. J Urol 1999;162:1185-1188.

74. Kershen RT, Fefer SD, Atala A. Tissue engineering therapies for the treatment of urinary incontinence and vesicoureteral reflux. World J Urol 2000;18:51-55.

75. Kershen RT, Yoo JJ, Moreland RB, Krane RJ, Atala A. Novel system for the formation of human corpus cavernosum smooth muscle tissue in vivo. J Urol 1998;159:43. Abstract 156 .

76. Kershen RT, Yoo JJ, Moreland RB, Krane RJ, Atala A. Reconstitution of human corpus cavernosum smooth muscle in vitro and in vivo. Tissue Eng 2002;8(3):515-524.

77. Park HJ, Yoo JJ, Kershen RT, Moreland RB, Atala A. Reconstruction of human corporal smooth muscle and endothelial cells in vivo. J Urol 1999;162:1106-1109.

78. Falke G, Yoo JJ, Kwno TG, Moreland R, Atala A. Formation of corporal tissue architecture in vivo using human cavernosal muscle and endothelial cells seeded on collagen matrices. Tissue Eng 2003;9(5):871-879.

79. Kwno TG, Yoo JJ, Atala A. Autologous penile corpora cavernosa replacement using tissue engineering techniques. J Urol 2002; 168:1754-1758.

80. Yoo JJ, Park HJ, Lee I, Atala A. Autologous engineering cartilage rods for penile reconstruction. J Urol 1999;162: 1119-1121.

81. Yoo JJ, Park HJ, Atala A. Tissue engineering applications for phallic reconstruction. World J Urol 2000;18:62-66.

82. Kim BS, Yoo JJ, Atala A. Engineering of human cartilage rods: potential application for penile protheses. J Urol 2002; 168(4):1794-1797.
83. Fauza DO, Fishman SJ, Mehegan K, Atala A. Videofetoscopically assisted fetal tissue engineering: bladder augmentation. J Pedriatr Surg 1998;33:7-12.

84. Atala A. Tissue engineering in urologic surgery. Urol Clin North Am 1998;25:39-50.

85. Atala A, Schlussel RN, Retik AB. Renal cell growth in vivo after attachment to biodegradable polymer scaffolds. J Urol 1995; 153:281A. Abstract 209.

86. Cieslinski DA, Humes HD. Tissue engineering of a bioartificial kidney. Biotechnol Bioeng 1994;43:678-681.

87. Humes HD. Cell therapy and tissue engineering for renal replacement therapy. Am J Kidney Dis 1998;32(6):xlii-xliv.

88. Sens DA, Detrisac CJ, Sens MA, Rossi MR, Wenger SL, Todd JH. Tissue culture of human renal epithelial cells used a defined serum-free growth formulation. Exp Nephrol 1999;7:344-352.

89. Van Kooten C, Lam S, Daha MR. Isolation, culture, characterization and use of human renal tubular epithelial cells. J Nephrol 2001;14(3):204-210.

90. Humes HD. Renal replacement devices. En Lanza RP, Langer R, Vacanti JP. editores. Principles of tissue engineering. $2^{\mathrm{a}}$ edición. San Diego, California. Academic Press 2000: 645-653.

91. Atala A. Tissue engineering of artificial organs. J Endourol 2000;14(1):49-57.

92. Machluf M, Orsola A, Atala A. Controlled release of therapeutic agents: slow delivery and cell encapsulation. World J Urol 2000;18: 80-83.

93. Machluf M, Orsola A, Boorjian S, Kershen R, Atala A. Microencapsulation of Leyding cells: a system for testosterone supplementation. Endocrinology 2003;144(11): 4975-4979.

94. Cilento BG, Freeman MR, Schneck FX, Retik AB, Atala A. Phenotypic and cytogenetic characterization of human bladder urothelia expanded in vitro. J Urol 1994;152: 665-670.

95. Liebert M, Wedemeyer G, Chang JH et al. Comparison of antigen expression on normal urothelial cells in tissue section and tissue culture. J Urol 1990;144:1288-1292.

96. Freeman MR, Schneck FX, Soker S et al. Human urothelial cells secrete and are regulated by heparin-binding epidermal growth factor-like growth factor (HB-EGF). J Urol 1995; 153:307A. Abstract 316.

97. Freeman MR, Yoo JJ, Raab G et al. Heparin-binding epidermal growth factor-like growth factor is an autocrine growth factor for human urothelial cells and is synthetized by epithelial and smooth muscle cells in the human bladder. J Clin Invest 1997;99:1028-1036.

98. Atala A. Tissue engineering in urology. Curr Urol Rep 2001;2(1):83-92.

99. Metwalli AR, Colvert JR, Kropp BP. Tissue engineering in urology: where are we going?. Curr Urol Rep 2003;4(2): 156-163.

100. Atala A. Tissue engineering, stem cells, and cloning for the regeneration of urologic organs. Clin Plast Surg 2003;30(4):649-667.

101. Atala A. Regenerative medicine and urology. BJU Int 2003;92 suppl. 1 :58-67.

102. Atala A. Tissue engineering perspectives for reconstructive surgery. En Walsh PC, Retik AB, Vaughan ED, Wein AJ. Editores. Campbell's Urology. 8 ${ }^{\mathrm{a}}$ Ed. Philadelphia. Ed. Saunders 2002: 2593-2622.

Dr. E. de Diego Rodríguez

C/ Miguel de Unamuno, 6 - 5o B

39012 Santander (Cantabria)

(Trabajo recibido el 26 febrero de 2004) 